\title{
Meisenheimer Complexes Bonded at Carbon and at Oxygen
}

\author{
Hao Chen, Huanwen Chen, and R. Graham Cooks \\ Department of Chemistry, Purdue University, West Lafayette, Indiana, USA
}

\begin{abstract}
The carbon-bonded gas-phase Meisenheimer complex of 2,4,6-trinitrotoluene (TNT) and the nitromethyl carbanion $\mathrm{CH}_{2} \mathrm{NO}_{2}^{-}(\mathrm{m} / \mathrm{z} 60)$ is generated for the first time by chemical ionization using nitromethane as the reagent gas. Collision-induced dissociation (CID) of the Meisenheimer complex furnishes deprotonated TNT, a result of the higher gas-phase acidity of TNT than nitromethane. The formation of Meisenheimer complexes with $\mathrm{CH}_{2} \mathrm{NO}_{2}^{-}$in the gas phase is selective to highly electron-deficient compounds such as dinitrobenzene and trinitrobenzene and does not occur with organic molecules with lower electron-affinity such as methanol, methylamine, propionaldehyde, acetone, ethyl acetate, chloroform, toluene, $m$-methoxytoluene, and even nitrobenzene and $p$-fluoronitrobenzene. As such, the reaction allows selective detection of TNT in mixtures. Meisenheimer complexes between $\mathrm{CH}_{2} \mathrm{NO}_{2}^{-}$and the three dinitrobenzene isomers display distinctive fragmentations. The oxygen-bonded $\sigma$-complex of TNT with the deprotonated hemiacetal anion $\mathrm{CH}_{3} \mathrm{OCH}_{2} \mathrm{O}^{-}(\mathrm{m} / \mathrm{z} 61)$, represents a different type of Meisenheimer complex. It displays characteristic fragmentation involving loss of $\mathrm{HNO}_{2}$ upon CID. The combination of a selective ion/molecule reaction (Meisenheimer complex formation) followed by a characteristic CID process provides a second novel and highly selective approach to the detection of TNT and closely related compounds in mixtures. The assay is readily implemented using neutral loss scans in a triple quadrupole mass spectrometer. Gas-phase reactions of denitrosylated TNT with benzaldehyde produce the corresponding dihydrofuran in an aldol condensation, a result that parallels the corresponding condensed-phase reaction. (J Am Soc Mass Spectrom 2004, 15, 998-1004) (c) 2004 American Society for Mass Spectrometry
\end{abstract}

$\mathrm{M}$ eisenheimer complexes, first proposed by Jackson [1] and later isolated by Meisenheimer [2], are anionic $\sigma$-complexes formed by covalent addition of nucleophiles to a ring carbon atom of electron-deficient aromatic and heteroaromatic substrates [3, 4]. It is believed that Meisenheimer complexes are key intermediates in nucleophilic aromatic substitution $\left(\mathrm{S}_{\mathrm{N}} \mathrm{Ar}\right)$ reactions (Scheme 1$)$. The chemistry of Meisenheimer complexes has a history stretching back more than 100 years and a tremendous amount of relevant work has been reported. Crystallography and NMR spectroscopy have played pivotal roles in the structural characterization of the $\sigma$-complexes [5] while visible spectroscopy has been the primary tool in kinetic and thermodynamic studies of complex-forming reactions in solution [6]. Except for theoretical investigations [7-10], very few studies have been reported on gas-phase Meisenheimer complexes, although gas-

Published online June 8, 2004

This article is dedicated with affection to Fred McLafferty in celebration of a life in mass spectrometry.

Address reprint requests to Dr. R. G. Cooks, Department of Chemistry, Purdue University, West Lafayette, IN 47907-1393, USA. E-mail: cooks@purdue.edu phase nucleophilic reactions of aromatic systems [1114] have been investigated. One exception is found in the work of Kebarle who measured both free energy and enthalpy changes for the formation of the Meisenherimer complex between fluoride and perfluorobenzene [15] using gas phase $\mathrm{F}^{-}$transfer equilibria. This author also investigated the complexes of substituted benzenes with the anions $\mathrm{CH}_{3} \mathrm{O}^{-}, \mathrm{F}^{-}, \mathrm{Cl}^{-}, \mathrm{Br}^{-}$, and $\mathrm{I}^{-}$ [16]. Yinon found that $[\mathrm{TNT}+\mathrm{H}]^{-}$, the hydride Meisenheimer complex of TNT, synthesized in the condensed phase, undergoes reduction and hydrolysis prior to ionization when analyzed through a heated exposure probe in a high-pressure ion source of mass spectrometry [17].

Nitroaromatics and related compounds, including TNT, have been used widely as explosives and their detection is an important issue. Gas-phase ionic reactions have been employed to improve the selectivity and sensitivity of detection of particular compounds by mass spectrometry [18-21]. Because nitroaromatics like TNT are typically electron-deficient due to the strong electron-withdrawing effect of the nitro group, studies exploring negative ion chemistry, including the formation of anionic Meisenheimer complexes from nitroaro- 


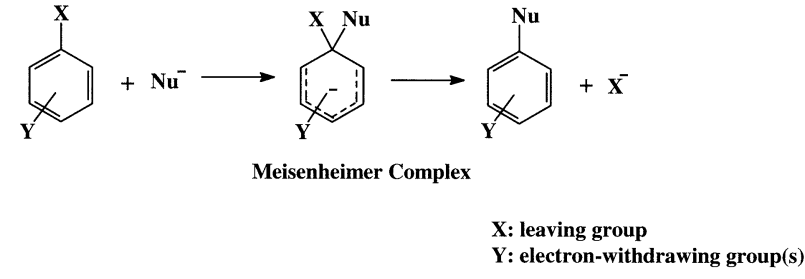

Scheme 1

matics in the gas phase, are potentially of great value. In addition, negative ion mass spectrometry increases the selectivity of ion production from the limited number of compound classes to which it is applicable; again, these include nitroaromatic compounds [22]. Another significant feature of TNT chemistry is the reactivity of its methyl protons ( $\mathrm{CH}$-acidity in DMSO [23], $\left.p \mathrm{~K}_{\mathrm{a}}=10.5\right)$, under the strong electron-withdrawing influence of the three nitro groups. Recently Rozhkov et al. [24] reported that TNT reacts readily in solution with electrophilic aldehydes $\mathrm{CF}_{3} \mathrm{CHO}$ and $\mathrm{CCl}_{3} \mathrm{CHO}$ to form the corresponding alcohols. In the presence of base, the resulting alcohols undergo smooth intramolecular cyclization to produce benzofurans (Scheme 2). However, an analogous reaction of TNT with aldehydes in the gas phase has not been reported before. It is sought here in an attempt to extend the parallels between solution and gas-phase reactivity.

This paper demonstrates for the first time the gasphase formation of the carbon- and oxygen-bonded Meisenheimer complexes of nitroaromatics with the nitromethyl carbanion $\mathrm{CH}_{2} \mathrm{NO}_{2}^{-}$and with the oxygencentered anion $\mathrm{CH}_{3} \mathrm{OCH}_{2} \mathrm{O}^{-}$, respectively. It also demonstrates potential applications of these reactions in distinguishing dinitrobenzene isomers and in selective detection of TNT in mixtures, a current challenging issue in analytical chemistry [25-28]. In addition, the gas-phase aldol-like condensation reaction of [TNT$\mathrm{NO}^{-}$( $m / z$ 197), a major TNT fragment ion, with benzaldehyde $\mathrm{PhCHO}$ followed by intramolecular cyclization to give rise to the derivatized benzofuran ion $\mathrm{m} / \mathrm{z} 257$ is reported.

\section{Experiments}

Experiments were carried out using a Finnigan TSQ-70 triple quadrupole mass spectrometer (Thermo Finnigan, San Jose, CA) with the ion source and manifold temperatures maintained at $150{ }^{\circ} \mathrm{C}$ and $70{ }^{\circ} \mathrm{C}$, respec-

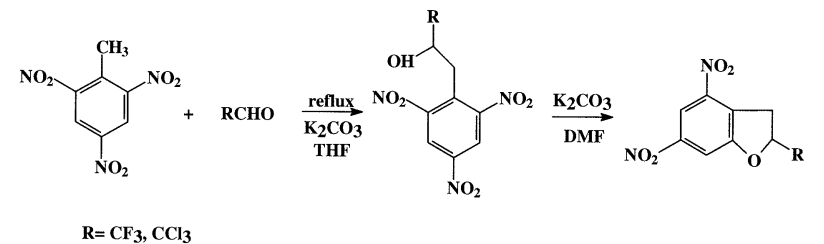

Scheme 2

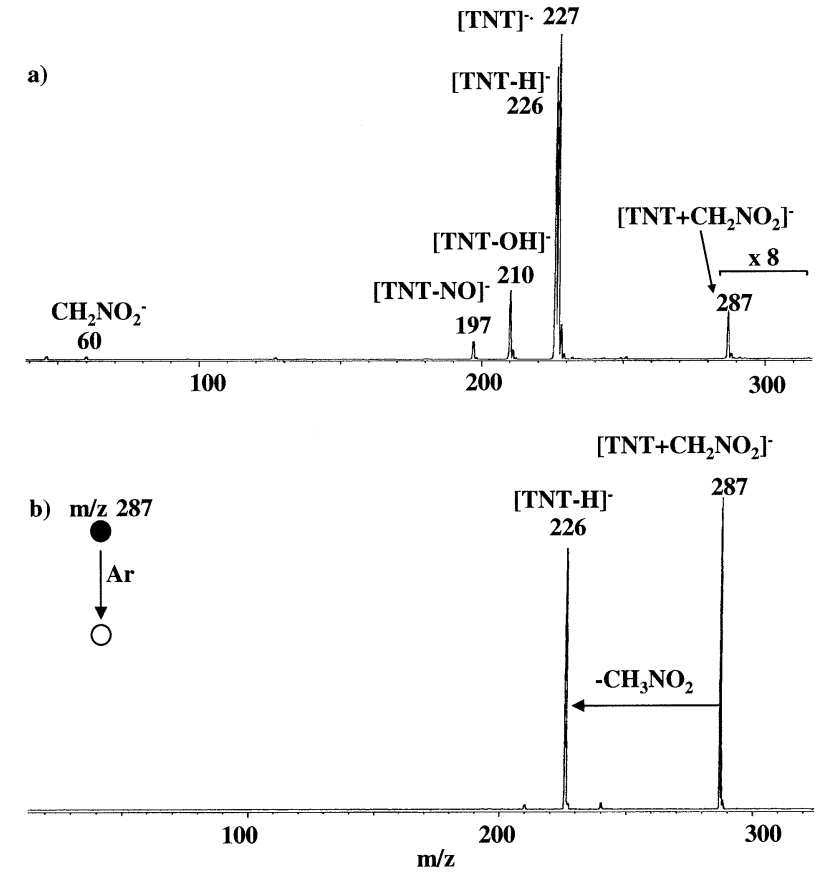

Figure 1. (a) Negative ion CI mass spectrum of TNT using $\mathrm{CH}_{3} \mathrm{NO}_{2}$ as the reagent gas; (b) CID product ion MS/MS spectrum of the Meisenheimer complex $\left[\mathrm{TNT}+\mathrm{CH}_{2} \mathrm{NO}_{2}\right]^{-}(\mathrm{m} / \mathrm{z} 287)$ using argon as target at a nominal $10 \mathrm{eV}$ collision energy.

tively. The reagent gas was allowed to leak into the chemical ionization source while the solid sample of interest was introduced by evaporation from a direct insertion probe. Neutral loss MS/MS spectra were recorded by selecting a particular neutral fragment value and scanning Q1 and Q3 simultaneously at the same rate. All compounds were commercially available and used without further purification.

\section{Results and Discussion}

\section{Carbon-Bonded Meisenheimer Complexes}

Carbon-bonded Meisenheimer complexes, such as $\sigma$-complexes of activated aromatics with enolate carbanions, have long been important in the pharmaceutical color tests [29]. The anion chosen to form Meisenheimer complexes with nitroaromatics in the gas phase is the nitromethyl carbanion $\mathrm{CH}_{2} \mathrm{NO}_{2}^{-}$. It was chosen because it is easily available and can be generated via deprotonation of nitromethane $\mathrm{CH}_{3} \mathrm{NO}_{2}$. Another reason for studying this anion is that it is a good nucleophile for new $\mathrm{C}-\mathrm{C}$ bond formation in the Henry or nitroaldol reaction [30]. Figure 1a displays the negative ion chemical ionization (CI) mass spectrum of TNT recorded using $\mathrm{CH}_{3} \mathrm{NO}_{2}$ as the reagent gas. In addition to the abundant TNT radical anion, TNT $^{-\cdot}(\mathrm{m} / \mathrm{z} 227)$, one observes the deprotonated molecule $[\mathrm{TNT}-\mathrm{H}]^{-}(\mathrm{m} / \mathrm{z}$ 226), fragments [TNT-OH] $]^{-}(m / z 210)$ and [TNT-NO] ${ }^{-}$ $(\mathrm{m} / \mathrm{z}$ 197), and a peak at $\mathrm{m} / \mathrm{z} 287$. This latter ion corresponds to either the complex [TNT $\left.+\mathrm{CH}_{2} \mathrm{NO}_{2}\right]^{-}$ 


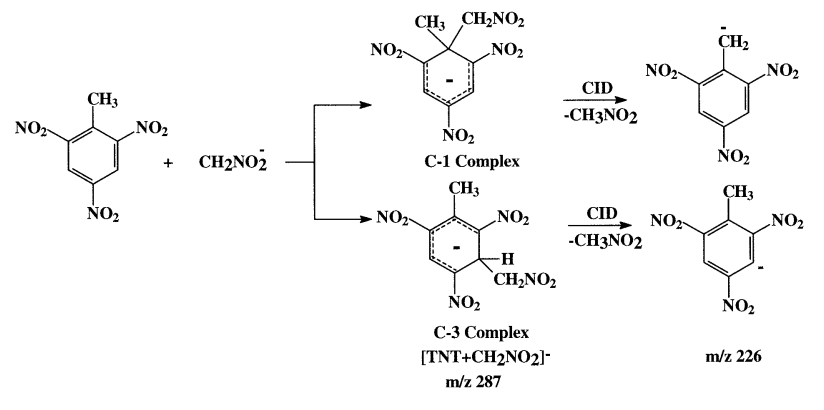

Scheme 3

formed by the addition of $\mathrm{CH}_{2} \mathrm{NO}_{2}^{-}(\mathrm{m} / z$ 60) to TNT or to the simple adduct of the deprotonated ion [TNT-H] ${ }^{-}$ $\left(m / z\right.$ 226) with neutral $\mathrm{CH}_{3} \mathrm{NO}_{2}$. The latter possibility was excluded by the observation of the isotopomeric ion $\left[\mathrm{TNT}+\mathrm{CD}_{2} \mathrm{NO}_{2}\right]^{-}$at $\mathrm{m} / z 289$ when nitromethane $\mathrm{CD}_{3} \mathrm{NO}_{2}$ was used as the reagent gas. The former possibility embraces three possible forms of the complex ion $\left[\mathrm{TNT}+\mathrm{CH}_{2} \mathrm{NO}_{2}\right]^{-}(\mathrm{m} / \mathrm{z} 287)$, a $\sigma$-bonded Meisenheimer complex, a noncovalently-bonded $\pi$-complex or a hydrogen-bonded complex between neutral TNT and ion $\mathrm{CH}_{2} \mathrm{NO}_{2}^{-}$. However, $\mathrm{CID}$ of the isolated complex ion [TNT $\left.+\mathrm{CH}_{2} \mathrm{NO}_{2}\right]^{-}(\mathrm{m} / z$ 287) and its isotopomeric ion [TNT $\left.+\mathrm{CD}_{2} \mathrm{NO}_{2}\right]^{-}(m / z$ 289) mainly yielded [TNT-H] ${ }^{-}(\mathrm{m} / \mathrm{z} 226)$ by loss of $\mathrm{CH}_{3} \mathrm{NO}_{2}$ or $\mathrm{CHD}_{2} \mathrm{NO}_{2}$ neutral, suggesting that deprotonation of TNT occurs during the CID process (Figure 1b) and strongly suggesting the $\sigma$-bonded Meisenheimer complex structure rather than the weakly-bonded $\pi$-complex structure. The fact that there is no $\mathrm{CH}_{2} \mathrm{NO}_{2}^{-}$peak generated from CID (Figure 1b) excludes the possibility of the hydrogen-bonded adduct. The reaction, as well as the proposed structure of the Meisenheimer complex, is illustrated in Scheme 3. Note that the Meisenheimer complex $(\mathrm{m} / \mathrm{z} 287)$ is proposed to occur as a mixture of two possible structures, the $\mathrm{C}-1$ and $\mathrm{C}-3$ complexes, both involving $\mathrm{C}-\mathrm{C}$ bond formation.

As suggested by Buncel [4, 8], in polar solvents like DMSO and methanol both C-1 and C-3 regioisomeric Meisenheimer adducts of substituted trinitrobenzenes may be observed for oxygen-centered nucleophiles such as the methoxide ion, depending on the temperature. For carbon-centered nucleophiles such as $\mathrm{CH}_{3} \mathrm{COCH}_{2}^{-}$, on the other hand, C-3 Meisenheimer adducts are both kinetically and thermodynamically favored. If this is also the case in the gas phase, the C-3 complex is expected to be the favored form of [TNT + $\left.\mathrm{CH}_{2} \mathrm{NO}_{2}\right]^{-}$. The fragment ion [TNT-H] ${ }^{-}(\mathrm{m} / \mathrm{z} 226)$ could be formed from either the $\mathrm{C}-1$ complex via $\beta$-elimination of $\mathrm{CH}_{3} \mathrm{NO}_{2}$ or from the $\mathrm{C}-3$ complex via $\alpha$-elimination. The fact that CID of the Meisenheimer complex does not yield substitution products-except for the deprotonation reaction-is probably due to the fact that the methyl group of TNT is not a good leaving group and that TNT has a higher gas-phase acidity $\left(\Delta \mathrm{G}_{\text {acid }}=\right.$ $309.0 \pm 2.0 \mathrm{kcal} / \mathrm{mol})[31]$ than $\mathrm{CH}_{3} \mathrm{NO}_{2}\left(\Delta \mathrm{G}_{\text {acid }}=349.7\right.$ $\pm 2.0 \mathrm{kcal} / \mathrm{mol}$ ) [32]. The occurrence of deprotonation in this case exactly coincides with the previous observation of Briscese and Riveros [11] of proton transfer in the gas-phase nucleophilic reactions of $\mathrm{CH}_{3} \mathrm{O}^{-}$with m-difluorobenzene $\mathrm{C}_{6} \mathrm{H}_{4} \mathrm{~F}_{2}$ leading to the production of $\mathrm{CH}_{3} \mathrm{OH}$ and $\mathrm{C}_{6} \mathrm{H}_{3} \mathrm{~F}_{2}^{-}$, since the higher acidity of $\mathrm{C}_{6} \mathrm{H}_{4} \mathrm{~F}_{2}$ $\left(\Delta \mathrm{G}_{\text {acid }}=366.3 \pm 2.0 \mathrm{kcal} / \mathrm{mol}\right)$ [33] compared to that of $\mathrm{CH}_{3} \mathrm{OH}\left(\Delta \mathrm{G}_{\text {acid }}=375.1 \pm 1.1 \mathrm{kcal} / \mathrm{mol}\right)$ [34], prevents the nucleophilic substitution reaction [11].

Experiments were also carried out to examine the specificity of Meisenheimer complex formation with the carbanion $\mathrm{CH}_{2} \mathrm{NO}_{2}^{-}$in the gas phase. Various compounds such as methanol, methylamine, propionaldehyde, acetone, ethyl acetate, chloroform, toluene and m-methoxytoluene were chosen to model alcohols, amines, aldehydes, ketones, esters, haloalkanes, hydrocarbons and ethers, respectively. The results show that none of these compounds forms adducts with $\mathrm{CH}_{2} \mathrm{NO}_{2}^{-}$ in the ion source. Even nitrobenzene and $p$-fluoronitrobenzene fail to complex with $\mathrm{CH}_{2} \mathrm{NO}_{2}^{-}$while dinitrobenzenes (DNB), 1-chloro-2,4-dinitrobenzene (CDNB) and 1,3,5-trinitrobenzene (TNB) do so. This phenomenon is in good agreement with the generalization that typically two or three electron-withdrawing groups located ortho and/or para to the site of nucleophilic attack are required to allow detection of anionic $\sigma$-complex formation in solution [3]. Nitrobenzene and even p-fluoronitrobenzene appear to be insufficiently electron-deficient to form Meisenheimer complexes with $\mathrm{CH}_{2} \mathrm{NO}_{2}^{-}$. It is apparent that the formation of Meisenheimer complex with $\mathrm{CH}_{2} \mathrm{NO}_{2}^{-}$is highly selective.

Among the three different substituted dinitrobenzene (DNB) isomers, meta-dinitrobenzene forms a much more abundant Meisenheimer complex with $\mathrm{CH}_{2} \mathrm{NO}_{2}^{-}$ than do the ortho and para isomers. Interestingly, these three Meisenheimer complexes [DNB $\left.+\mathrm{CH}_{2} \mathrm{NO}_{2}\right]^{-}(\mathrm{m} / \mathrm{z}$ 228) display distinctive fragmentation patterns upon CID. As shown in Figure 2, while $\left[o-\mathrm{DNB}+\mathrm{CH}_{2} \mathrm{NO}_{2}\right]^{-}$ $(\mathrm{m} / \mathrm{z} 228)$ gives two fragment ions $(\mathrm{m} / \mathrm{z} 60$ and 181) with comparable intensities by loss of neutral DNB and $\mathrm{HNO}_{2}$, the meta and para isomers yield unique fragment ion at $m / z 60$ and 181, respectively, suggesting this as a new and very rapid method of differentiating the three dinitrobenzene isomers [35]. The fragment ion $\mathrm{m} / \mathrm{z} 60$ corresponds to the carbanion $\mathrm{CH}_{2} \mathrm{NO}_{2}^{-}$and the most likely structure of the fragment ion of $\mathrm{m} / z 181$ is the phenide anion, formed through elimination of a hydrogen atom and nitro group, the product being resonance stabilized by an ortho or para nitro group. The absence of resonance stabilization explains the absence of this fragment ion in the case of the meta isomer.

As shown in Figure 3, an interesting fragment ion of $m / z 226$ is produced by loss of $\mathrm{HCl}$ during CID of the Meisenheimer complex $\left[\mathrm{CDNB}+\mathrm{CH}_{2} \mathrm{NO}_{2}\right]^{-}(\mathrm{m} / z$ 262). In contrast, the $\mathrm{S}_{\mathrm{N}} \mathrm{Ar}$ product $\mathrm{Cl}^{-}$was not observed even though $\mathrm{Cl}^{-}$is a good leaving group. This phenomenon provides another example of the fact that various reactions, including proton transfer and E2-elimination channels, compete with $S_{N} A r$ displacement in the gasphase nucleophilic substitution on aromatics [9]. Like 


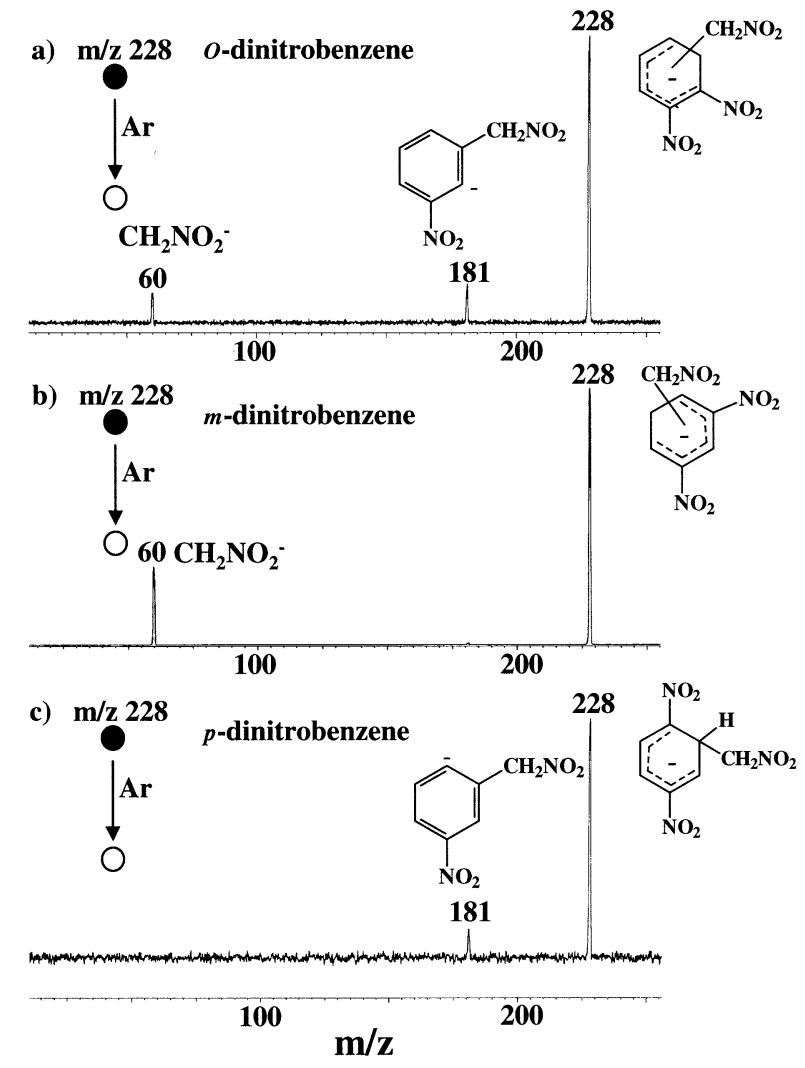

Figure 2. CID product ion MS/MS spectra of Meisenheimer complexes (a) $\left[o-\mathrm{DNB}+\mathrm{CH}_{2} \mathrm{NO}_{2}\right]^{-}(\mathrm{m} / \mathrm{z} 228) ;(\mathbf{b})[\mathrm{m}$-DNB + $\left.\mathrm{CH}_{2} \mathrm{NO}_{2}\right]^{-}$(m/z 228); (c) $\left[p-\mathrm{DNB}+\mathrm{CH}_{2} \mathrm{NO}_{2}\right]^{-}$(m/z 228) using argon as target at a nominal $10 \mathrm{eV}$ collision energy.

TNT, 1,3,5-trinitrobenzene (TNB) also forms a Meisenheimer complex $\left[\mathrm{TNB}+\mathrm{CH}_{2} \mathrm{NO}_{2}\right]^{-}(\mathrm{m} / \mathrm{z} 273)$ readily with the anion $\mathrm{CH}_{2} \mathrm{NO}_{2}^{-}$; the complex dissociates into $\mathrm{m} / \mathrm{z} 212$ and 226 by loss of $\mathrm{CH}_{3} \mathrm{NO}_{2}$ and $\mathrm{HNO}_{2}$ upon collision. The fragmentation behavior of these carbonbonded Meisenheimer complexes is summarized in Table 1.

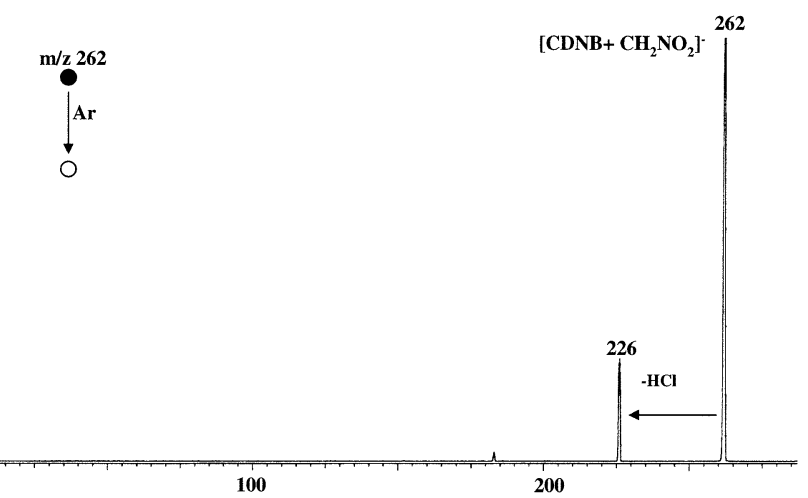

Figure 3. CID product ion MS/MS spectrum of the Meisenheimer complex $\left[\mathrm{CDNB}+\mathrm{CH}_{2} \mathrm{NO}_{2}\right]^{-}(\mathrm{m} / \mathrm{z} 262)$ using argon as target at a nominal $10 \mathrm{eV}$ collision energy.

\section{Oxygen-Bonded Meisenheimer Complexes}

A Meisenheimer complex $\left[\mathrm{TNT}+\mathrm{CH}_{3} \mathrm{OCH}_{2} \mathrm{O}\right]^{-}(\mathrm{m} / \mathrm{z}$ 288) of a different type is formed via negative ion $\mathrm{CI}$ of TNT using the vapor from a methanol-containing formaldehyde solution as the reagent gas (i.e., the hemiacetal $\mathrm{CH}_{3} \mathrm{OCH}_{2} \mathrm{OH}$ formed by the reaction of $\mathrm{HCHO}$ with $\mathrm{CH}_{3} \mathrm{OH}$ [36] is the reagent gas). The presence of hemiacetal $\mathrm{CH}_{3} \mathrm{OCH}_{2} \mathrm{OH}$ in the formaldehyde solution vapor was confirmed by observation of both the protonated hemiacetal $\mathrm{CH}_{3} \mathrm{OCH}_{2} \mathrm{OH}_{2}^{+}(\mathrm{m} / z$ 63) and the deprotonated hemiacetal $\mathrm{CH}_{3} \mathrm{OCH}_{2} \mathrm{O}^{-}(\mathrm{m} / \mathrm{z}$ 61) in the mass spectrum of the reagent gas. Also, $\mathrm{CID}$ of the ion $\mathrm{CH}_{3} \mathrm{OCH}_{2} \mathrm{OH}_{2}^{+}(\mathrm{m} / \mathrm{z} 63)$ gives rise to $\mathrm{CH}_{3} \mathrm{O}^{+}=\mathrm{CH}_{2}(\mathrm{~m} / \mathrm{z}$ 45) and $\mathrm{CH}_{3} \mathrm{OH}_{2}^{+}(\mathrm{m} / \mathrm{z} 33)$ by loss of $\mathrm{H}_{2} \mathrm{O}$ and $\mathrm{HCHO}$ and $\mathrm{CID}$ of $\mathrm{CH}_{3} \mathrm{OCH}_{2} \mathrm{O}^{-}(\mathrm{m} / \mathrm{z}$ 61) leads to the fragment ion $\mathrm{CH}_{3} \mathrm{O}^{-}(\mathrm{m} / \mathrm{z} 31)$ by loss of $\mathrm{HCHO}$. The oxygenbonded Meisenheimer complex [TNT $\left.+\mathrm{CH}_{3} \mathrm{OCH}_{2} \mathrm{O}\right]^{-}$ $(\mathrm{m} / \mathrm{z} 288)$ undergoes a characteristic fragmentation to give an ion $\mathrm{m} / \mathrm{z} 241$ by loss of $\mathrm{HNO}_{2}$ in addition to giving the fragment ion [TNT-H] $]^{-}(\mathrm{m} / z$ 226, Figure 4). The fragmentation pathway proposed to give rise to the ion $\mathrm{m} / \mathrm{z} 241$ is shown in Scheme 4; and it involves a C-3 Meisenheimer complex.

The formation of the TNT/Meisenheimer complex with $\mathrm{CH}_{3} \mathrm{OCH}_{2} \mathrm{O}^{-}$and its unique fragmentation behavior can be used to selectively detect TNT in mixtures. Considering that the radical anion $\mathrm{TNT}^{-}$. $\left(m / z\right.$ 227) also dissociates by loss of $\mathrm{HNO}_{2}(47 \mathrm{Da})$ upon CID, although to a much smaller extent compared to the complex [TNT $\left.+\mathrm{CH}_{3} \mathrm{OCH}_{2} \mathrm{O}\right]^{-}(\mathrm{m} / \mathrm{z}$ 288), a neutral loss MS/MS scam $[19,20]$ can be adopted to detect these two unique transitions for TNT. As a demonstration, a mixture of ethyl isovalerate, 2,4-dimethyl-3-hexanone and TNT was ionized using the hemiacetal $\mathrm{CH}_{3} \mathrm{OCH}_{2} \mathrm{OH}$ as the reagent gas. The two compounds, ethyl isovalerate and 2,4dimethyl-3-hexanone, were selected to model esthers and ketones as background contaminants. While the positive ion CI spectrum shown in Figure 5a is very complex (note the protonated peaks due to $\mathrm{HCHO}$, $\mathrm{CH}_{3} \mathrm{OH}, \mathrm{CH}_{3} \mathrm{OCH}_{2} \mathrm{OH}$ and ethyl isovalerate, 2,4dimethyl-3-hexanone and TNT at 31, 33, 63, 129, 131 and 228, respectively), the neutral loss scan spectrum $(\Delta \mathrm{m}=47 \mathrm{Da})$ in the negative ion mode (Figure $5 \mathrm{~b})$ is extremely simple and only displays two characteristic peaks associated with the two reactions of interest. These are due to $\mathrm{HNO}_{2}$ loss from TNT ${ }^{-\cdot}(\mathrm{m} / z$ 227) and $\left[\mathrm{TNT}+\mathrm{CH}_{3} \mathrm{OCH}_{2} \mathrm{O}\right]^{-}(\mathrm{m} / \mathrm{z}$ 288) and they occur without any interference from other compounds, clearly proving the presence of TNT. The high selectivity of this experiment stems from the combination of selective formation of the TNT/Meisenheimer complex and its characteristic fragmentation behavior. The additional advantages of such a detection method are that when fully developed, it should be fast and sensitive. The detection limit is under investigation. 
Table 1. Fragmentation of Meisenheimer complexes formed with $\mathrm{CH}_{2} \mathrm{NO}_{2}{ }^{-}$

\begin{tabular}{|c|c|c|c|}
\hline Compounds & Abbreviation & $\begin{array}{l}\text { Meisenheimer } \\
\text { complex } \mathrm{m} / \mathrm{z}\end{array}$ & $\begin{array}{l}\text { Major fragment ions } \\
m / z \text { (neutral lost) }\end{array}$ \\
\hline & $o$-DNB & 228 & $\begin{array}{c}60(-\mathrm{DNB}) \\
181\left(-\mathrm{HNO}_{2}\right)\end{array}$ \\
\hline & $m$-DNB & 228 & 60 (-DNB) \\
\hline & $p$-DNB & 228 & $181\left(-\mathrm{HNO}_{2}\right)$ \\
\hline & CDNB & 262 & $226(-\mathrm{HCl})$ \\
\hline & TNB & 273 & $\begin{array}{l}212\left(-\mathrm{CH}_{3} \mathrm{NO}_{2}\right) \\
226\left(-\mathrm{HNO}_{2}\right)\end{array}$ \\
\hline & TNT & 287 & $226\left(-\mathrm{CH}_{3} \mathrm{NO}_{2}\right)$ \\
\hline
\end{tabular}

\section{Aldol-Like Condensation of [TNT-NO $]^{-}$ with Benzaldehyde}

As mentioned above, the $\mathrm{C}-\mathrm{H}$ bond in the methyl group of gas phase TNT is fairly acidic due to strong activation by the nitro groups. The interaction between TNT and benzaldehyde ( $\mathrm{PhCHO})$, in the gas phase was therefore examined. Figure 6 shows the negative ion CI mass spectrum of TNT using PhCHO as the reagent gas. The peak observed at $\mathrm{m} / \mathrm{z} 303$ is assigned to the addition product of PhCHO with [TNT-NO] ${ }^{-}(\mathrm{m} / \mathrm{z}$ 197), one of major TNT fragment ions, as confirmed by the result that the corresponding addition product ion $\mathrm{m} / \mathrm{z} 255$ was observed when $\mathrm{CH}_{3} \mathrm{CH}_{2} \mathrm{CHO}$ was used instead of $\mathrm{PhCHO}$ as the reagent gas. The ion $\mathrm{m} / \mathrm{z} 303$ is proposed in Scheme 5 to be produced via an aldol-like condensation of PhCHO with [TNT-NO] $]^{-}(\mathrm{m} / \mathrm{z}$ 197) in the form of the electrophilic 2-hydroxy-4,6-dinitrobenzyl carbanion, generated from $\mathrm{TNT}^{-}$by loss of NO. The existence of the 2-hydroxy-4,6-dinitrobenzyl anion $(\mathrm{m} / \mathrm{z}$ 197) as one isomeric ion of [TNT-NO] ${ }^{-}(\mathrm{m} / \mathrm{z}$ 197) is supported by HF/3-21 + G calculations using the Gaussian 2003 program [37] which show that its energy is very close to that of the 2-methyl-3,5-dinitrophenoxide anion, the other isomer of [TNT-NO] ${ }^{-}(\mathrm{m} / \mathrm{z}$ 197). The former is

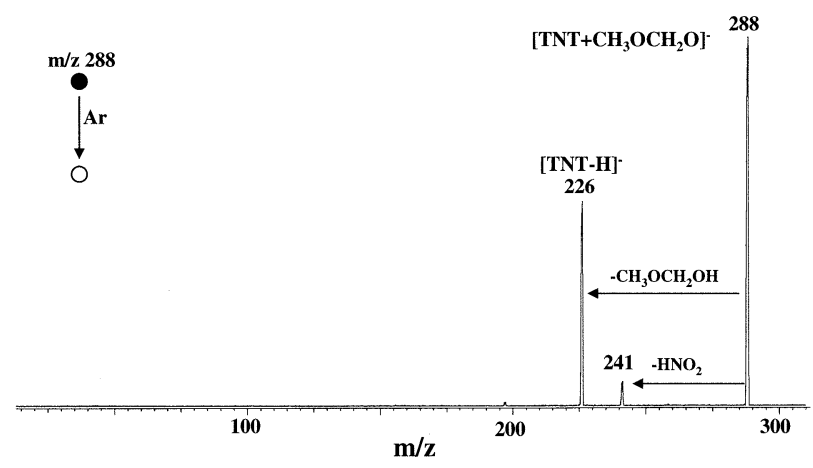

Figure 4. CID product ion MS/MS spectrum of the Meisenheimer complex [TNT $\left.+\mathrm{CH}_{3} \mathrm{OCH}_{2} \mathrm{O}\right]^{-}(\mathrm{m} / \mathrm{z} 288)$ using argon as target at a nominal $10 \mathrm{eV}$ collision energy. higher in energy by only $2.7 \mathrm{kcal} / \mathrm{mol}$, indicating that these two isomeric ions might be convertible via an ortho hydrogen shift. The benzyl anion can be stabilized by resonance (Scheme 5) while 2-methyl-3,5-dinitrophenoxide anion does not have significant resonance stabilization. Upon CID, the ion of $\mathrm{m} / \mathrm{z} 303$ undergoes intramolecular cyclization with loss of $\mathrm{NO}_{2}$ to yield an ion of $\mathrm{m} / \mathrm{z} 257$, assigned as the cyclic benzofuran ion (Figure 6b). This reaction is proposed to occur via attack at the ortho carbon of the benzene ring by the bare oxygen anion (Scheme 5), analogous with the condensed-phase reaction reported by Rozhkov [24]. This unique fragmentation is missing for the ion of $\mathrm{m} / \mathrm{z} 255$ generated from the aliphatic aldehyde $\mathrm{CH}_{3} \mathrm{CH}_{2} \mathrm{CHO}$, indicating that the cyclization is aldehyde-dependent. Rozhkov also showed that the analogous reaction in Scheme 2 occurs readily for electron-withdrawing groups such as $\mathrm{R}=\mathrm{CCl}_{3}$ or $\mathrm{CF}_{3}$ but not for $\mathrm{R}=\mathrm{H}$ [24]. In addition, ions $\mathrm{m} / \mathrm{z} 197,273$, and 286 arise from the fragmentation of the ion $\mathrm{m} / \mathrm{z} 303$ as well by loss of $\mathrm{PhCHO}, \mathrm{NO}^{\circ}$ and $\mathrm{OH}$; respectively. The cyclic benzofuran ion $(\mathrm{m} / \mathrm{z} 257)$ is also present in the spectrum shown in Figure 6a, suggesting the occurrence of the aldol-like condensation and subsequent cyclization reactions of 2-hydroxy-4,6-dinitrobenzyl carbanion $(\mathrm{m} / \mathrm{z}$ 197) with PhCHO in the ion source (Scheme 5). Further dissociation of the ion of $\mathrm{m} / \mathrm{z} 257$ forms ions $\mathrm{m} / \mathrm{z} 151$ and 211 by loss of $\mathrm{PhCHO}$ and $\mathrm{NO}_{2}$, respectively. However, the analogous reaction of $\mathrm{PhCHO}$ with the carbanion [TNT-H] ${ }^{-}(m / z 226)$ is missing, probably due to the relative low nucleophilicity of [TNT-H] $]^{-}$compared with 2-hydroxy-4,6-dinitrobenzyl carbanion $(\mathrm{m} / \mathrm{z}$ 197) since the ion $[\mathrm{TNT}-\mathrm{H}]^{-}$has one more ortho electron-

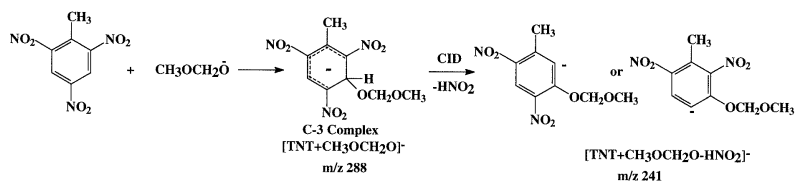

Scheme 4 

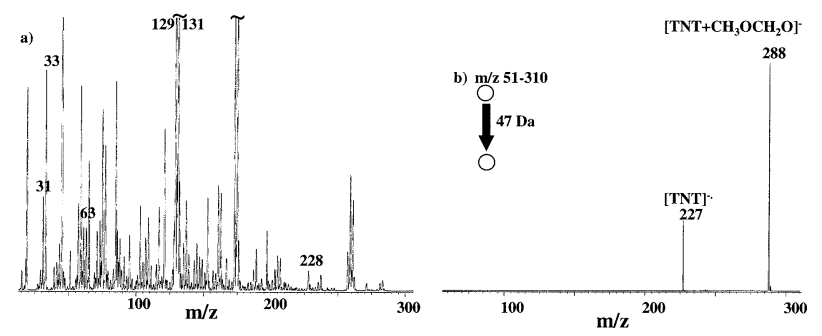

Figure 5. (a) Positive ion CI mass spectrum of a mixture of ethyl isovalerate, 2,4-dimethyl-3-hexanone and TNT using the hemiacetal $\mathrm{CH}_{3} \mathrm{OCH}_{2} \mathrm{OH}$ as the reagent gas; (b) Constant neutral loss $\mathrm{MS} / \mathrm{MS}$ spectrum in the negative ion mode.

withdrawing nitro group. The ortho nitro group stabilizes the carbanion $[\mathrm{TNT}-\mathrm{H}]^{-}$but also reduces the nucleophilicity of $[\mathrm{TNT}-\mathrm{H}]^{-}$.

\section{Conclusions}

This study of the Meisenheimer complexes of nitroaromatics bonded at carbon and at oxygen provides a method of distinguishing dinitrobenzene isomers and provides two new, highly selective approaches to the detection of TNT in mixtures. The selective ion/mole-

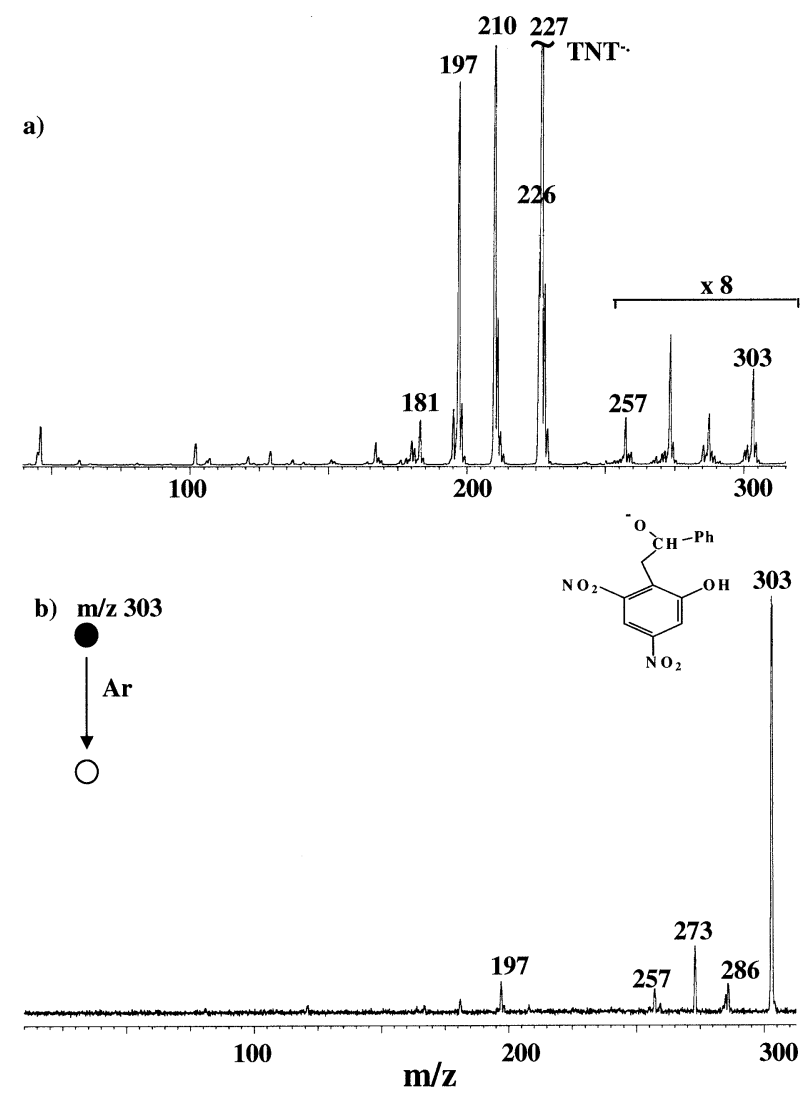

Figure 6. (a) Negative ion CI mass spectrum of TNT using $\mathrm{PhCHO}$ as the reagent gas; (b) CID product ion MS/MS spectrum of the ion of $\mathrm{m} / \mathrm{z} 303$ using argon as target at a nominal $10 \mathrm{eV}$ collision energy.

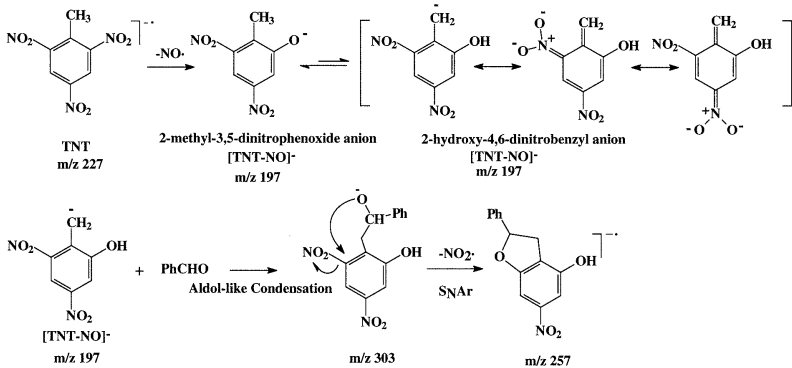

Scheme 5

cule reactions of the oxygen-bonded Meisenheimer complexes are reminiscent of the selective phosphorus ester chemistry used to recognize chemical warfare agents [20]. In both this and in the earlier experiments, constant neutral loss/gain scans proved useful in examining complex mixtures for compounds containing the specific functional group of interest. The gas-phase aldol-like condensation and intramolecular cyclization reaction of [TNT-NO] $]^{-}$with benzaldehyde to yield derivatized benzofurans is also potentially valuable for the detection of TNT using mass spectrometry. Other points of note are that the CID behavior of Meisenheimer complexes is useful in studies of reactions that compete with aromatic nucleophilic substitution $\mathrm{S}_{\mathrm{N}} \mathrm{Ar}$ reactions in the gas phase. In addition, the observed parallels observed between the solution and gas-phase reactions of TNT with aldehydes are noteworthy.

\section{Acknowledgments}

This work was supported by the Office of Naval Research (N00014-02-1-0975).

\section{References}

1. Jackson, C. J.; Gazzolo, F. H. On Certain Colored Substances Derived from Nitro Compounds. CXVII. Am. Chem. J. 1900, 23, 376.

2. Meisenheimer, J. Ueber Reactionen Aromatischer Nitro Korper. Justus Liebigs Ann. Chem. 1902, 323, 205.

3. Terrier, F. Rate and Equilibrium Studies in Jackson-Meisenheimer Complexes. Chem. Rev. 1982, 82, 77.

4. Buncel, E.; Dust, J. M.; Terrier, F. Rationalizing the Regioselectivity in Polynitroarene Anionic $\sigma$-Adduct Formation. Relevance to Nucleophilic Aromatic Substitution. Chem. Rev 1995, 95, 2261.

5. Strauss, M. J. Anionic Sigma Complexes. Chem. Rev. 1970, 70, 667.

6. Crampton, M. R. Meisenheimer Complexes. Adv. Phys. Org. Chem. 1969, 7; p 211.

7. Zheng, Y.-J.; Ornstein, R. L. Mechanism of Nucleophilic Aromatic Substitution of 1-Chloro-2,4-Dinitrobenzene by Glutathione in the Gas Phase and in Solution. Implications for the Mode of Action of Glutathione S-Transferases. J. Am. Chem. Soc. 1997, 119, 648.

8. Buncel, E.; Tarkka, R. M.; Dust, J. M. AM1 Studies on the Stabilities of Anionic $\sigma$-Complex Regioisomers: Thermodynamics of Regioselectivity in the Reaction of Methide, Methoxide, and Hydroxide Anions with Electron-Deficient Aromatics. Can. J. Chem. 1994, 72, 1709. 
9. Simkin, B. Y.; Gluz, E. B.; Glukhovtsev, M. N.; Minkin, V. I. Theoretical Study of Mechanisms of Aromatic Nucleophilic Substitution in the Gas Phase. Themochem. 1993, 103, 123.

10. Strauss, M. J.; Fleischman, S.; Buncel, E. A Theoretical Investigation by the MNDO Method of the Explosive Complexes of Hydroxide Ion with 1,3,5-Trinitrobenzene and 4,6-Dinitrobenzofuroxan. Themochem. 1985, 22, 37.

11. Briscese, S. M. J.; Riveros, J. M. Gas Phase Nucleophilic Reactions of Aromatic Systems. J. Am. Chem. Soc. 1975, 97, 230.

12. Ingemann, S.; Nibbering, N. M. M.; Sullivan, S. A.; DePuy, C. H. Nucleophilic Aromatic Substitution in the Gas Phase: The Importance of Fluoride Ion/Molecule Complexes Formed in Gas-Phase Reactions between Nucleophiles and Some Alkyl Pentafluorophenyl Ethers. J. Am. Chem. Soc. 1982, 104, 6520.

13. Ingemann, S.; Nibbering, N. M. M. Gas-Phase Reactions of Anions with 2-, 3-, and 4-Fluoroanisole. J. Org. Chem. 1983, 48, 183.

14. Bowie, J. H.; Stapleton, B. J. Electron Impact Studies. CXIII. Aromatic Nucleophilic Substitution in the Gas Phase. The Dinitrobenzenes. An Ion Cyclotron Resonance Study. Aust. J. Chem. 1977, 30, 795.

15. Dillow, G. W.; Kebarle, P. Fluoride Affinities of Perfluorobenzenes $\mathrm{C}_{6} \mathrm{~F}_{5} \mathrm{X}$. Meisenheimer Complexes in the Gas Phase and Solution. J. Am. Chem. Soc. 1988, 110, 4877.

16. Paul, G.; Kebarle, P. Stabilities of Complexes of $\mathrm{Br}^{-}$with Substituted Benzenes (SB) Based on Determination of the Gas-Phase Equilibria $\mathrm{Br}^{-}+\mathrm{SB}=(\mathrm{BrSB})^{-}$. J. Am. Chem. Soc. 1991, 113, 1148-1154.

17. Yinon, J.; Johnson, J.; Bernier, U. R.; Yost, R. A.; Mayfield, H. T.; Mahone, W. C.; Vorbeck, C. Reactions in the Mass Spectrometry of a Hydride Meisenheimer Complex of 2,4,6Trinitrotoluene (TNT). J. Mass Spectrom. 1995, 30, 715-722.

18. Heath, T. G.; Allison, J.; Watson, J. T. Selective Detection of the Tolyl Cation among Other $\left[\mathrm{C}_{7} \mathrm{H}_{7}\right]$ Isomers by Ion/Molecule Reaction with Dimethyl Ether. J. Am. Soc. Mass Spectrom. 1991, 2, 270 .

19. Chen, H.; Zheng, X.; Yang, P.; Cooks, R. G. Reduction of Nitroaromatics into Arylnitrenium Ions by Vinyl Halide Cation. Chem. Commun. 2004, 688.

20. Chen, H.; Zheng, X.; Cooks, R. G. Ketalization of Phosphonium Ions by 1,4-Dioxane: Selective Detection of the Chemical Warfare Agent Simulant DMMP in Mixtures Using Ion/ Molecule Reactions. J. Am. Soc. Mass Spectrom. 2003, 3, 181.

21. Petzold, C. J.; Leavell, M. D.; Leary, J. A. Screening and Identification of Acidic Carbohydrates in Bovine Colostrum by Using Ion/Molecule Reactions and Fourier Transform Ion Cyclotron Resonance Mass Spectrometry: Specificity toward Phosphorylated Complexes. Anal. Chem. 2004, 76, 203.

22. Yinon, J. Mass Spectrometry of Explosives: Nitro Compounds, Nitrate Esters and Nitramines. Mass Spectrom Rev. 1982, 1, 257.

23. Matthews, R. G.; Drummond, G. T. Providing One-Carbon Units for Biological Methylations: Mechanistic Studies on Serine Hydroxymethyltransferase, Methylenetetrahydrofolate Reductase, and Methyltetrahydrofolate-Homocysteine Methyltransferase. Chem. Rev. 1990, 90, 1275.

24. Rozhkov, V.; Kuvshinov, A.; Shevelev, S. Interaction of 2,4,6Trinitrotoluene and Its Analogues with Aldehydes. Synthesis of Benzoannelated Heterocycles from the Products of Condensation. Synthetic Commun. 2002, 32, 1465.

25. Meurer, E. C.; Chen, H.; Riter, L. S.; Cotte-Rodriguez, I.; Eberlin, M. N.; Cooks, R. G. Gas-Phase Reactions for Selective
Detection of the Explosives TNT and RDX. Chem. Commun. 2004, 40.

26. Yinon, J. Detection of Explosives by Electronic Noses. Anal. Chem. 2003, 75, 99A.

27. Pinnaduwage, L. A.; Gehl, A.; Hedden, D. L.; Muralidharan, G.; Thundat, T.; Lareau, R. T.; Sulchek, T.; Manning, L.; Rogers, B.; Jones, M.; Adams, J. D. Explosives: A Microsensor for Trinitrotoluene Vapor. Nature 2003, 425, 474.

28. Battle, R.; Carlsson, H.; Tollbaeck, P.; Colmsjoe, A.; Crescenzi, C. Enhanced Detection of Nitroaromatic Explosive Vapors Combining Solid-Phase Extraction-Air Sampling, Supercritical Fluid Extraction, and Large-Volume Injection-GC. Anal. Chem. 2003, 75, 3137.

29. Kovar, K. A. The Meisenheimer Complex-The Basis of Pharmaceutical Color Reactions. Pharm. Unserer Z. 1972, 1, 16.

30. Luzzio, F. A. The Henry reaction: recent examples. Tetrahedron 2001, 57, 915

31. Koppel, I. A.; Taft, R. W.; Anvia, F.; Zbu, S.-Z.; Hu, L.-Q.; Sung, K.-S.; DesMarteau, D. D.; Yagupolskii, L. M.; Yagupolskii, Y. L.; Ignat'ev, N. V.; Kondratenko, N. V.; Volkonskii, A. Y.; Vlasov, V. M.; Notario, R.; Maria, P.-C. The Gas-Phase Acidities of Very Strong Neutral Bronsted Acids. J. Am. Chem. Soc. 1994, 116, 3047.

32. Bartmess, J. E.; Scott, J. A.; McIver, R. T. The Gas Phase Acidity Scale from Methanol to Phenol. J. Am. Chem. Soc. 1979, 101, 6047.

33. Buker, H. H.; Nibbering, N. M. M.; Espinosa, D.; Mongin, F.; Schlosser, M. Additivity of Substituent Effects in the Fluoroarene Series: Equilibrium Acidity in the Gas Phase and Deprotonation Rates in Ethereal Solution. Tetrahed. Lett. 1997, 38, 8519.

34. Ramond, T. M.; Davico, G. E.; Schwartz, R. L.; Lineberger, W. C. Vibronic Structure of Alkoxy Radicals via Photoelectron Spectroscopy. J. Chem. Phys. 2000, 112, 1158.

35. Zhao, X.; Yinon, J. Characterization and Origin Identification of 2,4,6-Trinitrotoluene through its By-Product Isomers by Liquid Chromatography-Atmospheric Pressure Chemical Ionization Mass Spectrometry. J. Chromatogr. A 2002, 946, 125.

36. Carey, F. A.; Sundberg, R. J. Advanced Organic Chemistry, 2nd ed. Part A: Structure and Mechanisms; Plenum Publishing Corporation: New York, 1984; p 326.

37. Frisch, M. J.; Trucks, G. W.; Schlegel, H. B.; Scuseria, G. E.; Robb, M. A.; Cheeseman, J. R.; Montgomery, J.; Vreven, T.; Kudin, K. N.; Burant, J. C.; Millam, J. M.; Iyengar, S. S.; Tomasi, J.; Barone, V.; Mennucci, B.; Cossi, M.; Scalmani, G.; Rega, N.; Petersson, G. A.; Nakatsuji, H.; Hada, M.; Ehara, M.; Toyota, K.; Fukuda, R.; Hasegawa, J.; Ishida, M.; Nakajima, T.; Honda, Y.; Kitao, O.; Nakai, H.; Klene, M.; Li, X.; Knox, J. E.; Hratchian, H. P.; Cross, J. B.; Adamo, C.; Jaramillo, J.; Gomperts, R.; Stratmann, R. E.; Yazyev, O.; Austin, A. J.; Cammi, R.; Pomelli, C.; Ochterski, J. W.; Ayala, P. Y.; Morokuma, K.; Voth, G. A.; Salvador, P.; Dannenberg, J. J.; Zakrzewski, V. G.; Dapprich, S. W.; Daniels, A. D.; Strain, M. C.; Farkas, O.; Malick, D. K.; Rabuck, A. D.; Raghavachari, K.; Foresman, J. B.; Ortiz, J. V.; Cui, Q.; Baboul, A. G.; Clifford, S.; Cioslowski, J.; Stevanov, B. B.; Liu, G.; Liashenko, A.; Piskorz, P.; Komaromi, I.; Martin, R. L.; Fox, D. J.; Keith, T.; Al-Laham, M. A.; Peng, C. Y.; Nanayakkara, A.; Challacombe, M.; Gill, P. M. W.; Johnson, B.; Chen, W.; Wong, M. W.; Gonzalez, C.; Pople, J. A. Gaussian 2003; Gaussian, Inc.: Pittsburgh, PA, 2003. 